\title{
Persistent decay of fresh xylem hydraulic conductivity varies with pressure gradient and marks plant responses to injury
}

\author{
Sara Bonetti ${ }^{12^{*}}$, Daniel Breitenstein ${ }^{2}$, Simone Fatichi ${ }^{3,4}$, Jean-Christophe Domec ${ }^{5,6}$, and Dani \\ $\mathrm{Or}^{2,7}$ \\ ${ }^{\mathbf{1}}$ Bartlett School of Environment, Energy and Resources, University College London, WC1H 0NN \\ London, UK
}

${ }^{2}$ Soil and Terrestrial Environmental Physics, Department of Environmental Systems Science, ETH Zürich, 8092 Zürich, Switzerland

${ }^{3}$ Institute of Environmental Engineering, ETH Zurich, Zürich, Switzerland

${ }^{4}$ Department of Civil and Environmental Engineering, National University of Singapore, Singapore

${ }^{5}$ Bordeaux Sciences Agro, UMR 1391 INRA ISPA, 33175 Gradignan Cedex, France

${ }^{6}$ Nicholas School of the Environment, Duke University, Durham, NC 27708, USA

${ }^{7}$ Division of Hydrologic Sciences, Desert Research Institute, Reno, NV 89512, USA.

*To whom correspondence should be addressed. E-mail: s.bonetti@ucl.ac.uk

\section{Keywords:}

Xylem hydraulic conductivity | Plant hydraulic traits | Plant vascular system | Xylem conductivity measurements | Sapflow

Running head: Xylem hydraulic conductivity

This article has been accepted for publication and undergone full peer review but has not been through the copyediting, typesetting, pagination and proofreading process which may lead to differences between this version and the Version of Record. Please cite this article as doi: $10.1111 /$ pce. 13893 


\section{Abstract:}

Defining plant hydraulic traits is central to the quantification of ecohydrological processes ranging from land-atmosphere interactions, to tree mortality, and water-carbon budgets. A key plant trait is the xylem specific hydraulic conductivity $\left(K_{x}\right)$, that describes the plant's vascular system capacity to transport water. While xylem's vessels and tracheids are dead upon maturity, the xylem is neither inert nor deadwood, various components of the sapwood and surrounding tissue remaining alive and functional. Moreover, the established definition of $K_{x}$ assumes linear relations between water flux and pressure gradient by tacitly considering the xylem as a "passive conduit”. Here we reexamine this notion of an inert xylem by systematically characterizing xylem flow in several woody plants using $K_{x}$ measurements under constant and cyclic pressure gradients. Results show a temporal and pressure gradient dependence of $K_{x}$. Additionally, microscopic features in "living branches" are irreversibly modified upon drying of the xylem thus differentiating the macroscopic definition of $K_{x}$ for living and dead xylem. The findings highlight the picture of the xylem as a complex and delicate conductive system whose hydraulic behavior transcends a passive gradient-based flow. The study sheds new light on xylem conceptualization, conductivity measurement protocols, in situ long-distance water transport, and ecosystem modeling. 


\section{Introduction}

Long-distance water transport in plants occurs primarily through the xylem, where non-living vascular conduits provide mechanical support and simultaneously allow water flow from roots to leaves under tension at rates sufficient for maintaining transpiration and preventing leaf desiccation (Pickard, 1981; Tyree and Zimmermann, 2002; Larcher, 2003; Stroock et al., 2014). Xylem conduits are of two general types: tracheids are typically less than $10 \mathrm{~mm}$ long with diameters of approximately 10-20 $\mu \mathrm{m}$ connected via linearly aligned bordered pits (Pickard, 1981; Tyree and Ewers, 1991; Tyree and Zimmermann, 2002; Jensen et al., 2016), and vessels (mostly found in angiosperms) composed of vertically aligned elements connected through porous perforation plates. Vessels are connected via fields composed of tens to hundreds of bordered pits, can reach meters in length, and have diameters between approximately 10 and $500 \mu \mathrm{m}$ (Tyree and Zimmermann, 2002; Brown, 2013; Olson and Rosell, 2013; Jensen et al., 2016). While the xylem conduit cells die by undergoing autolysis and lose their protoplasts to become hydraulically active (Dixon, 1914; Rioux et al., 1998; Sperry, 2011), studies have shown that part of the sapwood and surrounding live tissue (parenchyma) remain alive and functional and thus cannot be treated as inert deadwood (see, e.g., Stroock et al., 2014; De Micco et al., 2016; Nardini et al., 2011; Schenk, 2018; Morris et al., 2018; Jacobsen et al., 2018; Schenk et al., 2018). The intricate structure of the xylem has evolved to support the transport of water under metastable conditions at relatively high flow rates (Sperry, 2011; Jensen et al., 2016). To safely transport water across a range of environmental conditions and external stresses, plants employ a number of safety measures such as highly compartmentalized and redundant vascular networks (Brodersen et al., 2014; Choat et al., 2008), bordered pits with nanoporous membranes (Brodersen et al., 2014; Choat et al., 2008; Jensen et al., 2016), and stomata control in the leaves (Monteith 1995; Martin-StPaul et al., 2017). An additional and less studied response mechanism is attributed to prevention of pathogen and embolism spread by local occlusion of xylem conduits with gels and tyloses secreted by the xylem parenchyma cells. This plant 
response has been observed for a range of biotic and abiotic stresses, such as wounding, infections, freezing, drought, and natural aging (Rioux et al., 1998; Crews et al., 2003; Kitin et al., 2010; De Micco et al., 2016; Sun et al., 2008). We will study the implications of such plant responses on the interpretation of hydraulic conductivity measurements.

At the heart of the Cohesion-Tension (CT) theory (Dixon and Joly, 1895; Tyree, 1997; Brown, 2013) is the ascent of sap through the xylem under tension generated at air-water interfaces in the leaves. Such theory has been framed in quantitative terms by Van den Honert (1948) who proposed a Ohm's analogue for water flow in the soil-plant-atmosphere continuum, where the water flux through a discrete plant segment is proportional to the product of the hydraulic conductivity of that region and water potential difference, thus replacing the detailed mechanisms of the ascent of sap by a theory involving bulk flow properties (Brown, 2013). The local (midday) water potential in the xylem in non-drought conditions typically ranges between -0.5 and $-2.0 \mathrm{MPa}$, reaching much lower values (up to approximately -10 MPa) under water stress conditions as well as in desert and seawater environments (Sperry, 2011; Stroock et al., 2014; Jensen et al., 2016). However, the overall pressure gradient necessary to sustain the xylem flow is relatively low, generally ranging between 0.01 and $0.04 \mathrm{MPa} \mathrm{m}^{-}$ ${ }^{1}$ (Dixon 1914; Bauerle et al., 1999; Domec et al., 2007; Sperry, 2011). Within this framework, the xylem hydraulic conductivity $K_{x}\left[\mathrm{~kg} \mathrm{~m}^{-1} \mathrm{~s}^{-1} \mathrm{MPa}^{-1}\right]$ emerges as a key trait for the description of the plant's ability to sustain the long-distance water transport required for transpiration. It measures the ability of a plant's vascular system to transport water and is defined as the flux $Q$ [ $\left.\mathrm{kg} \mathrm{s}^{-1}\right]$ for a given driving force $\Delta h$ [MPa] normalized by the length of the segment $L[\mathrm{~m}]$, and referenced to the crosssectional area of the xylem $A_{x}\left[\mathrm{~m}^{2}\right]$,

$$
K_{x}=\frac{Q L}{A_{x} \Delta h}
$$

Xylem conductivity is generally measured by applying a hydraulic driving force (hydrostatic or by means of vacuum chambers) and the outflow is measured using flowmeters, balances, or pipettes (Sperry 
et al., 1988; Melcher et al., 2012). The underlying assumptions of these methods and the definition of $K_{x}$ in Eq. (1) are that the system may attain steady state (i.e., the flow rate is constant in time for a given pressure gradient) and exhibits a linear relationship between flow rate and pressure gradient (Domec et al., 2007; Melcher et al., 2012). However, various experimental studies have provided contrasting evidence. As early as 1914, Dixon (1914) observed a persistent decline in water flow over time, with a more rapid drop in the flow for higher pressure gradients (see Fig. 1a). More recently, studies have shown evidence of a non-linear relationship between $K_{x}$ and pressure gradient (Peel, 1965; Giordano et al., 1978; Domec et al., 2007) as well as a decline in $K_{x}$ over time (e.g., Sperry et al., 1988; Espino and Schenk, 2010; Melcher et al., 2012; Kelso et al., 1963; Canny et al., 2007; Jacobsen and Pratt, 2012).

The observed xylem sensitivity to the applied pressure gradient has been attributed to several mechanisms, including progressive air blockage, gel release in response to wounding, clogging, and non-laminar flow. Although the mechanisms responsible for the observed behavior are not yet fully understood, they all point to the notion that the xylem cannot be regarded as a collection of purely inert conduits, but rather as a more complex and dynamic system responding to external forcing. Possible non-linearities in the relationships between flux and pressure gradient, if ignored when modeling plantwater relations, might lead to errors in the predictions of plant water status and transpiration fluxes (Domec et al., 2007). Additionally, typical pressure gradients $(\Delta h / L)$ experienced by living trees (i.e., in the range of 0.01 and $0.04 \mathrm{MPa} \mathrm{m}^{-1}$ ) are considerably lower than those often applied during laboratory measurements (Domec et al., 2007; Espino and Schenk, 2010; Cochard et al., 2009). In fact, measurements of $K_{x}$ under steady-state mode are usually conducted on branches with sample lengths between $\approx 4$ and $30 \mathrm{~cm}$, with average applied pressures of about $10 \mathrm{kPa}$, thus providing typical pressure gradients in the range 0.03 and $0.25 \mathrm{MPa} / \mathrm{m}$ (a compilation of studies is listed in Table $\mathbf{S 1}$ in the Supplementary Information, SI). Additionally, when flow-centrifuge techniques are used to determine xylem vulnerability to embolism, applied transient pressure gradients through the samples are generally 
between approximately 0.15 and $2.5 \mathrm{MPa} / \mathrm{m}$ (see, e.g., Cochard et al., 2005). Clearly, if $K_{x}$ is nonlinearly related to the applied pressure, measurements obtained at pressures different from those experienced in planta might not be representative of real conditions. Furthermore, branches being exposed to pressure gradients higher than those at which they generally operate might experience damage (i.e., structural damage of pit membranes due to physical and chemical stresses - see, e.g., Hacke et al., 2001; Plavcová et al., 2013; Hillabrand et al., 2016), such that estimated $K_{x}$ might not be representative of intact living plants. These issues have led to the proposal of using low pressure heads in flow-centrifuge measurements to avoid the risk of torus aspiration at high pressure gradients (Bouche et al., 2015).

In addition to flux sensitivity to the applied pressure gradients, experimental measurements of $K_{x}$ might be further altered by other mechanisms, that have been invoked to explain a frequently observed decline in $K_{x}$ measurements. For example, studies have shown sensitivity of xylem hydraulic conductivity to the sap ionic strength and osmolarity (Trifilò et al., 2008; López-Portillo et al., 2005). This has further challenged the traditional description of the xylem as inert deadwood (Melcher et al., 2012; Stroock et al., 2014), although autonomous response of swelling tissues (e.g., bordered pits membranes (Nardini et al., 2011)) could be implicated. Zimmermann (1978) first observed a higher hydraulic conductivity for stems perfused with tap water compared to distilled water. More recently, a number of studies (e.g., Van Ieperen et al., 2000; Zwieniecki et al., 2001, 2004; Nardini et al., 2007; Domec et al., 2007) observed changes in $K_{x}$ in relation to variations in the ionic concentration of xylem sap (i.e., higher $K_{x}$ values for higher ionic strengths, and lower values for higher $\mathrm{pH}$ values), suggesting an ability of the xylem to exert local and autonomous control on flow at the level of individual vessels (López-Portillo et al., 2005; Nardini et al., 2011; Stroock et al., 2014). Xylem tissue response to various external stresses (e.g., wounding) by producing mucilage (Rioux et al., 1998; Crews et al., 2003; Kitin et al., 2010; Jacobsen and Pratt (2012); De Micco et al., 2016) is likely to further impact the xylem hydraulic functioning (i.e., through clogging, reduced surface tension, increased viscosity) thus altering 
any experimental observation in which release of mucilage might occur from wound-stimulated xylem parenchyma cells (Crews et al., 2003). For example, Jacobsen and Pratt (2012) have observed a decline in $K_{x}$ in flushed branches of $V$. vinifera, which was attributed to vessel occlusion by gels produced either as a wounding response or in relation to refilling of embolized vessels. Other studies further suggested the formation and coalescence of air bubbles to explain the observed decline in measured $K_{x}$ (Canny et al., 2007; Espino and Schenk, 2010). More recently, Tobin et al. (2013) observed a reduction in conductivity loss during repeated centrifugation by carefully handling the stem ends to avoid blockage due to air drying - although Umebayashi et al. (2019) attributed such a loss in conductivity to mechanical fatigue of the inter-conduit pit membranes during pressure cycling rather than to branch drying. We note, however, that some studies have found conductivity measurements to remain stable - Sperry et al. (1988), for example, showed that perfusion solutions containing formaldehyde could prevent the decline in conductivity during continuous measurements by arresting microbial growth.

Motivated by observations of nonlinear relations between the flow through the xylem system and pressure gradients and the question of a living xylem response, the study aims to systematically characterize the pressure-flux relationships across a wide range of woody plant species. The study combines xylem conductivity measurements under various pressure gradients and across multiple species with anatomical observations and theoretical considerations to validate the picture of a complex and delicate system whose hydraulic behavior goes beyond that of passive gradient-based flow. Specifically, we tested the following hypotheses: i) xylem hydraulic conductivity measurements depend upon the hydraulic gradient applied; ii) observed declines in $K_{x}$ measurement over time are due to an active wounding response of the xylem tissues with the production of gel clogging the xylem conduits; iii) air invasion and drying irreversibly modify xylem transport properties; and iv) complex microscopic xylem features (e.g., xylem network topology, redundancy of flow paths) affect the macroscopic definition of $K_{x}$. 


\section{Materials and Methods}

\subsection{Plant material, sample preparation, and hydraulic conductivity measurements}

Experiments were conducted for a range of gymnosperms and angiosperms representing diverse anatomical functional groups (tracheid bearing species as well as vessel bearing species with either diffuse-porous or ring-porous wood). Sampled tracheid-bearing species include Atlas cedar (Cedrus atlantica), Austrian pine (Pinus nigra), European yew (Taxus baccata), ginkgo (Ginkgo biloba), Lawson cypress (Chamaecyparis lawsoniana), giant sequoia (Sequoiadendron giganteum), and Norway spruce (Picea abies); diffuse-porous species include European hornbeam (Carpinus betulus), Norway maple (Acer platanoides), silver birch (Betula pendula), and Turkish hazel (Corylus colurna), while field elm (Ulmus minor) was the only ring-porous species sampled. A detailed list of all the species sampled in each experiment together with mean sample dimensions is provided in Tables $\mathbf{1}$ and $\mathbf{2}$, while Tables S3-S10 in the SI list details for each branch and measurement. The sampling bias towards tracheid-bearing species stems from the availability at the time of sampling and from avoiding collecting branches from deciduous species in wintertime.

Samples were collected in the early morning from a hospital park neighboring the ETH central campus in Zürich. Living branches were cut underwater and immediately transported to the laboratory. Samples were prepared by cutting small branch segments $(L \approx 5 \mathrm{~cm})$ under water in preparation for flow measurements. Branch segments were generally sampled between nodes. While branch segment length was considered sufficient to properly account for both lumen and pit resistances in the system, we note that $L$ was longer than the typical vessel length only for some of the species analyzed here (e.g. reported values for Acer platanoides provide mean vessel lengths of approximately $2.4 \mathrm{~cm}$ - see Jacobsen et al. (2012); Lens et al. (2011)). The length of the branch segment was shorter than the maximum vessel length for some species (e.g., Ulmus minor, see Martín et al. (2013)), and we cannot 
rule out the presence of open vessels in some of the segments used for hydraulic measurements. To limit the potential of wound reaction that may cause clogging of the xylem conduits, a section of the bark (approximately $5 \mathrm{~mm}$ ) was removed from the distal parts of the branch segments. Subsequently, the ends of the branch segments were trimmed with a clean razor blade. Branches were then inserted in silicone tubes and connected to a tubing system (see Fig. S1). For standardization of the flow behavior we have used degassed and filtered $(0.22 \mu \mathrm{m}) \mathrm{KCl}$ solution $(0.5 \mathrm{~g} / \mathrm{L})$, while silver ions bacteriocide (1 Micropur pill per $1 \mathrm{~L}$ water) was added to inhibit bacterial growth (Beikircher and Mayr, 2009; Mayr et al., 2006). The branches were kept under water for the entire sample preparation procedure. We did not flush the stems (except in the case of re-saturation experiments, see below) to avoid pressurizing the xylem and potentially causing internal structural damage.

The experimental setup (Fig. S1) allowed to measure flow through four branches simultaneously during a measurement. Each measurement is distinguished in the SI and throughout the text via an alphanumerical code ranging from V03 to V87 (note that we removed measurements where unexpected technical issues occurred). The branch hydraulic conductivity was measured by applying a hydrostatic pressure gradient that was controlled by adjusting the height of the fluid reservoir where the branch segments were immersed relative to an outlet placed below (hence flow through a branch was induced by tension and not positive pressure). The cumulative outflow from each branch segment was collected in individual beakers that were placed on balances to measure the rate of outflow. To suppress evaporation, we used beakers with long inlets and placed wet sponges around to maintain high air relative humidity. The xylem hydraulic conductivity $\left(K_{x}\right)$ was then computed according to Eq. (1), where $\Delta h$ is the hydrostatic pressure applied, and $A_{x}$ is defined as $A_{x}=\pi d^{2} / 4, d$ being the sample diameter (mean between inlet and outlet values) of the branch (without bark).

\subsection{Constant and cyclic pressure experiments}


A set of 15 measurements (4 branches were observed per measurement, see Table S3) was conducted by applying constant pressure heads $(\Delta h)$ only, whereas 19 additional measurements (Tables S7-S8) were performed by applying pressure steps in cycles of 20 to 60 minutes to measure the influence of different pressure gradients (and the potential for hysteretic flow behavior). In general, the hydrostatic pressure applied $(\Delta h)$ varied between 2 and $90 \mathrm{~cm}$ (see Tables 1 and 2), which, assuming an average sample length equal to $5 \mathrm{~cm}$, corresponded to $\Delta h / L$ between approximately 0.005 and $0.2 \mathrm{MPa} \mathrm{m}^{-1}$, the lower value being analogous to those generally experienced by living plants, the higher being more similar to those often applied in laboratory measurements (Domec et al., 2007) - see Table S1 in the SI.

To identify hydraulically active conduits under high and low pressure gradients, we performed an additional experiment (Table S11), in which crystal violet dye (0.2 gr per liter) was added to the $\mathrm{KCl}$ solution for four cypress (Chamaecyparis lawsoniana) and four elm (Ulmus minor) branches. Two branches per species were subjected to low $(\Delta h=10 \mathrm{~cm})$ and high $(\Delta h=60 \mathrm{~cm})$ pressure heads, respectively. After the flow measurement was run for approximately 20 hours, cross sections at $1 \mathrm{~cm}$ from the inlet were cut to visualize the conductive area.

Experiments were also conducted to evaluate the robustness of the measurements to the choice of branch length $L$ as well as to $\mathrm{KCl}$ concentration (see Table S4 in the SI for details and discussion below). Specifically, results from short branches (approximately $5 \mathrm{~cm}$ long) were compared to those for longer branches (approximately $10 \mathrm{~cm}$ ) for cedar, pine, and cypress samples. Two measurements were conducted to test the effect of increased $\mathrm{KCl}$ concentration (from 0.5 to $2 \mathrm{~g} / \mathrm{L}$ ) on $K_{x}$ for 4 yew and 4 elm samples.

A small set of measurements during the early phases of the study was conducted under constant positive pressure applied by a regulated water "bladder" (Table 2 and Table S9), to examine the effects of positive pressure application (as reported in certain studies) relative to application of suction as has been done in the other experiments reported here. 
The $222 K_{x}$ measurements from this study were further compared to 1447 values from the TRY plant trait database (Kattge et al., 2011; Kattge et al., 2020) retrieved from https://www.trydb.org (accessed September 2018), and a subset of the TRY database comprising 558 measurements (i.e., woody species from Manzoni et al. (2013) - see below for details).

\subsection{Branch cutting and flow reversal experiments}

Additional experiments were performed to test possible hypotheses (e.g., bubble formation, clogging due to gel production or debris) regarding the observed time and pressure dependence of the hydraulic conductivity measurements. Specifically, approximately 15-20 hours after starting the experiment, either we switched inlet and outlet in order to reverse the flow within the branch (hereafter referred to as "flow reversal experiments", Table S6) or we cut the first 1-1.5 cm of the branch inlet (“branch cutting experiments”, Table S5). Trimming the inlet would remove any clogging material (gel, debris) and potentially allows a recovery in conductivity. Conversely, flow reversal experiments were performed to test the hypothesis that observed declines in $K_{x}$ measurement over time might be due to bubble formation (at the initial flow restrictions within the sample) which should be pushed out after the flow reversal (Canny et al., 2007). A summary of the species analyzed in these experiments together with their mean dimensions and ranges of pressure heads applied is provided in Table 1.

\subsection{Xylem drying experiments}

We investigated experimentally potential effects of air invasion and subsequent (partial) xylem drying on hydraulic conductivity measurements using the same branch samples described above for $K_{x}$ determination (after their re-saturation and removal of all air). Specifically, we first evaluated $K_{x}$ of the intact xylem in fully hydrated conditions (same procedure as the constant pressure experiments) by measuring the flow rate for approximately 3 to 4 hours for four cypress and four elm samples. The 
branch segments were subsequently unpacked and dried under a fan for a time variable between 8 and 20 hours (see Table 2 and Table S10 in the SI for experimental details). After cutting one $\mathrm{cm}$ of the inlet to remove any clogging material and cleaning both inlet and outlet with a razor blade, the branches were re-packed in silicone tubes and re-saturated using a vacuum pump for 30 minutes. We then proceeded with the measurement of $K_{x}$ of the first dried and then re-saturated branches.

\section{Results}

\subsection{Time and pressure gradient dependence of xylem hydraulic conductivity}

Fig. 1b shows the typical behavior observed during a constant pressure experiment: the flow rate $Q$ (and consequent $K_{x}$ value) decreases over time, with a more pronounced drop in conductivity at higher pressure gradients. Such a behavior is consistent with observations from Dixon (1914) (Fig. 1a), both suggesting a temporal and pressure dependence of the $K_{x}$ measurement. Such a temporal pattern of decay was consistently observed in most of the constant-pressure experiments (Fig. S2), as displayed in Fig. 2a showing the temporal evolution of $K_{x}$ (normalized by its maximum value observed during each experiment): at low pressure gradients $\Delta h / L$ the drop in $K_{x}$ after 800 minutes was, on average, lower than the drop observed at higher pressure gradients (i.e., 35\% and 60\% decrease in $K_{x}$ for $\Delta h / L<5$ $\mathrm{m} / \mathrm{m}$ and $\Delta h / L \geq 5 \mathrm{~m} / \mathrm{m}$, respectively). The conductivity started to drop after 50 to 100 minutes from the beginning of the measurement. We did not observe major differences in the magnitude and timing of conductivity decay across species with different anatomical traits - we note however that this might be due to the limited number of angiosperm (compared to gymnosperms) samples analyzed here. The observed relative behavior of high and low pressure gradients was robust to the choice of $\mathrm{KCl}$ concentration as well as branch length $L$ (see Figs. S3-S4 in the SI for details).

A consequence of the gradual decay in $K_{x}$ is the apparent hysteretic behavior when cycles of pressure gradients are applied, as evident from Fig. 3 showing results for four yew (Taxus baccata) 
branch segments (approximately $5 \mathrm{~cm}$ long). An important aspect of the flow measurements reported here is the use of very low pressure gradients (e.g., $\Delta h / L=1 \mathrm{~m} / \mathrm{m}$ ) that sufficed to initiate and sustain the flow. The temporal decay in $K_{x}$ observed after the first few cycles at low pressure gradient values is commensurate with the drop in $K_{x}$ observed for the constant pressure experiments. However, the subsequent application of higher pressure gradients (e.g., $\Delta h / L=14 \mathrm{~m} / \mathrm{m}$ ) resulted in a further decrease in $K_{x}$, which did not recover to its original value when remeasured at lower pressure gradients (Fig. 4). A compilation of the results from all the cyclic pressure gradient experiments is summarized in Fig. 4 (see Figs. S7-S12 in the SI for detailed results pertaining to each experiment), exhibiting both the temporal decay and pressure gradient dependence of the $K_{x}$ measurements. We note, however, that in the cyclic experiments there tend to be confounding pressure and time effects. The two effects can be in part disentangled by analyzing the $K_{x}-\Delta h$ plots (Fig. 3c and figures in the SI) where the color code represents time, so that symbols with the same color show measurements taken at comparable times from the beginning of the experiment. While there is a clear effect of time, measurements taken during the same cycle also show a pressure dependence of the $K_{x}$ value, with higher $K_{x}$ for lower pressure gradients. This is also apparent from Fig. 4 where measurements taken at approximately the same time from the beginning of the experiment (i.e., same color) show a decrease in $K_{x}$ with the pressure gradient applied.

Results from branch cutting experiments are presented in Fig. 2e (see also Fig. S5) and show, on average, a recovery of $\approx 90 \%$ and $125 \%$ of the initial $K_{x}$ at high and low pressure gradients, respectively. Results from flow reversal experiments (Fig. 2f and Fig. S6) show, on average, little (for $\Delta h / L \geq 5 \mathrm{~m} / \mathrm{m}$ ) to no (for $\Delta h / L<5 \mathrm{~m} / \mathrm{m}$ ) recovery in the measured $K_{x}$ after reversing the flow (Fig. 2f). 
Measurements of pectin concentration in the xylem outflow (see SI for details) were performed to test the hypothesis of a reduction in xylem flow due to a wound-stimulated release of mucilage and showed an initial release of pectin with a subsequent drop in concentration (see Fig. 5).

\subsection{Pressure-driven xylem conduits activation}

To identify hydraulically active conduits, we performed additional experiments using dyed water in two contrasting species, namely Lawson cypress (Chamaecyparis lawsoniana) and field elm (Ulmus minor). Results (Fig. 6) show an increased pathway activation with increasing applied pressure gradient: on average, the stained area was $27 \pm 19 \%$ and $65 \pm 17 \%$ of the total cross-sectional area for low and high pressure gradients, respectively. Particularly, while the overall increase in pathway activation (i.e., the number of conduits becoming hydraulically active and contributing to water transport) was consistent between the two species, a higher portion of the total area was activated, on average, for the cypress compared to the elm, possibly due to the contrasting anatomical features (i.e., tracheids vs. ring-porous wood, respectively).

\subsection{Comparison of measured xylem hydraulic conductivity with literature data}

Fig. 7a compares data from the TRY Plant Trait Database with the 222 measurements from this study. Among our measurements, we included maximum $K_{x}$ values obtained from the constant pressure experiments, maximum $K_{x}$ obtained from the first cycles (before the application of high pressures) during pressure cycles experiments, and initial $K_{x}$ obtained from experiments with pressure tank (before the application of higher pressure gradients - see Figs. S13-S14). A compilation of all the measurement details and results is provided in the SI (Tables S3-S10). In general, measured $K_{x}$ values were close to literature data. The maximum values of $K_{x}$ obtained here were relatively insensitive to the applied pressure gradient (slightly higher values for lower pressure, but similar magnitude), while the main 
differences were observed in the temporal decay (see distributions in Fig. 2b-d). The TRY dataset showed, on average, higher conductivities and spanned a larger range of $K_{x}$ values, with significant differences between the mean conductivities of the TRY versus the here presented values (results from a two-sample $t$-test as well as mean and standard deviations for each $K_{x}$ dataset are provided in Table S2). The larger range spanned by the TRY dataset might be related not only to the greater number of species included, but also to the different measurement protocols. Specifically, the definition of the conductive area $A_{x}$ in Eq. (1) plays a key role in the determination of $K_{x}$ as evident from Fig. 7b, where measurements from a subset of the TRY database (i.e., woody species from Manzoni et al. (2013)) were subdivided based on the definition of $A_{x}$. In particular, there was not a significant difference (Table S2 in the SI) between the $K_{x}$ values from this study and the subset from Manzoni et al. (2013) where $A_{x}=$ $A_{t}$ (i.e., the cross-sectional area used to compute $K_{x}$ is equal to the total branch cross section excluding the bark). Conversely, mean $K_{x}$ values from this study differ significantly from those computed assuming $A_{x}$ equals either the branch cross section excluding pith $\left(A_{S}\right)$ or the conductive area obtained from staining $\left(A_{c}\right)$ - see Table S2. Results obtained for gymnosperms in this study showed a reasonably good agreement with the TRY subset (Fig. 7d), while $K_{x}$ values obtained here for angiosperms were significantly lower than those reported in Manzoni et al. (2013) (Fig. 7c).

\subsection{Re-saturation experiments: effect of air invasion and partial xylem drying}

Results from the re-saturation experiments are shown in Fig. 8 (see also Fig. S15 in the SI). After the drying and re-saturation procedure, we observed a reduction in maximum $K_{x}$ of $\approx 90 \%$ for 8 cypress branches (at both high and low pressure gradients) and $\approx 60 \%$ for 2 elm branches subjected to high pressure gradients (an example is shown in Fig. 8b, while detailed results for all the measurements are provided in Fig. S15). Only 2 elm branches subjected to low pressure gradients displayed a total recovery in the initial $K_{x}$ (see Fig. S15d in the SI). 


\subsection{Comparison with modeled transpiration fluxes}

Fig. 9 compares theoretical predictions of transpiration fluxes (computed from Eq. (1) for different pressure gradients and sapwood areas as a function of $K_{x}$ ) with published estimates of hourly transpiration per unit of leaf (the 99 percentile of daytime values for fully developed canopies) obtained from multi-year ecohydrological simulations via the T\&C model in 53 locations across the world characterized by woody vegetation cover (Fatichi et al., 2012; Fatichi and Pappas, 2017). Additional details on the T\&C model and simulations are provided in the SI. The comparison in Fig. 9 shows that gradients of $4 \mathrm{~m} / \mathrm{m}$ are sufficient to sustain maximum transpiration fluxes.

\section{Discussion and conclusions}

\subsection{Decay of xylem hydraulic conductivity}

Xylem hydraulic conductivity measurements with freshly cut branches (under water) showed a temporal decay in hydraulic conductivity values for both gymnosperms and angiosperms. This decay resulted in an apparent hysteretic behavior when cyclic pressure gradients were applied. A similar hysteretic behavior has been observed in measurements of root conductivity (Tyree et al., 1994) and by Cochard et al. (2009) (albeit at much higher pressure gradients), and was related to changes in solute concentration. To rule out possible effects of hydrogels swelling in pit membranes as a potential cause of the observed decrease in $K_{x}$, we used $\mathrm{KCl}$ solution (Zwieniecki et al., 2001) and conducted additional experiments with various values of $\mathrm{KCl}$ concentrations to illustrate the persistence of the observed $K_{x}$ decay across a range of ionic concentrations (see Fig. S3 in the SI). Furthermore, any reduction in $K_{x}$ as potentially related to initial lateral flow to fill cells and extra-cellular spaces (Espino and Schenk, 2010) has been discarded as the branches are kept in saturated conditions for the entire duration of the experiment setup and measurement. While the presence of native emboli cannot be ruled out and might 
have been responsible for the initial increase in $K_{x}$ observed in very few samples (see Fig. Fig. 2a and Fig. S2), this did not impact the observed reduction in $K_{x}$ which was consistent across species and samples taken at different times. Attribution of the $K_{x}$ reduction to bubble formation (Canny et al., 2007; Espino and Schenk, 2010) is unlikely due to the very low pressure gradients compatible with conditions in the plant, and the consistent decrease across experiments and tree species that is unlikely to be triggered by such nucleation events. In addition, the hypothesis of bubble formation does not explain the observed higher drop in $K_{x}$ with higher pressure gradients. Thus, while the potential occurrence of bubble formation and coalescence cannot be ruled out in some experiments, it is unlikely to provide an explanation for the systematic decline in xylem conductivity and its consistent dependence on the applied pressure gradient.

The observed decline in $K_{x}$ is attributed primarily to an active wounding response of the xylem tissue at the plane of the branch cut. This highlights a potential role of the living tissue surrounding dead xylem conduits that could actively respond to different environmental conditions including wounding (e.g., by insects, wind-induced mechanical damage, and similar events). Evidence suggests that such response could involve the production of mucilage substances capable of clogging the xylem conduits and reducing the flow (Dixon, 1914; Tyree and Ewers, 1991; Espino and Schenk, 2010; Melcher et al., 2012; Jacobsen et al., 2018, 2015; Crews et al., 2003). The effect in terms of $K_{x}$ decay was proportionally more significant under higher pressure gradients leading to the speculation that higher pressure gradients transport mucilage deeper into the branch segment (in proportion to the induced flow). The hypothesis of a reduction in xylem flow due to a wound-stimulated release of mucilage is further corroborated by measurements of pectin concentration (considered an important component of mucilage) in the xylem outflow (see SI for details) showing an initial release of pectin from wounded xylem and a subsequent drop in concentration (see Fig. 5). 
Other mechanisms that might contribute to the observed decline in conductivity include a passive wound response with debris being carried and pushed within the xylem (Sperry et al., 1988; Espino and Schenk, 2010) as well as possible damage and deformation of the pit membranes, with a more pronounced effect at higher pressure gradients (Espino and Schenk, 2010; Hacke et al., 2001; Hillabrand et al., 2016). These hypotheses are in line not only with the observed decline in $K_{x}$, but also with the higher magnitude of such decline observed at higher pressure gradients: in such conditions gel and debris would be pushed deeper within the conduits, while pit membranes could be subjected to a more pronounced deformation (Domec et al., 2006).

The sensitivity of the measurements to the applied pressure gradient has important implications for the correct interpretation of laboratory experiments, which need to be performed at pressures similar to those experienced in planta (i.e., $\lesssim 0.04 \mathrm{MPa} / \mathrm{m}$ ) in order to be representative of real conditions. Additionally, mucilage release in response to external stresses might further affect other invasive water transport methods (e.g. sap flow, stem psychrometers) where wound-induced gel production might result in a local reduction of the actual flow (Peters et al., 2018).

\subsection{Air invasion and drying irreversibly modify xylem transport properties}

We further pointed to the destructive role of air invasion that may have stretched and torn inter-conduit pit membranes (Petty and Puritch, 1970; Petty, 1972; Domec et al., 2006; Cochard et al., 2009), explaining potentially why the measured $K_{x}$ of dried and subsequently re-saturated branches was noticeably and consistently lower that the value of $K_{x}$ in fully hydrated conditions (Fig. 8a). The overall reduction in $K_{x}$ observed after air invasion might be related to a weakening of the xylem system resulting from internal morphological changes caused by the drying and/or damage or loosening of the pit membranes during the dehydration procedure (Hacke et al., 2001; Hillabrand et al., 2016). This highlights the fact that measurements of xylem conductivity for physiological and ecological 
applications should be carried out over intact and hydrated branches, as opposed to measurements over dried wood samples commonly performed in wood science (Kelso et al., 1963; Glass and Zelinka, 2010).

\subsection{Micro- and macroscopic xylem responses}

The xylem macroscopic and microscopic behaviors were shown to be tightly intertwined, with a gradient-based sequence of pathways activation suggesting that redundancy in the xylem network is needed not only to overcome friction, but also as a safety measure to allow system functioning when some or several conduits are embolized, damaged, or clogged (Brodersen et al., 2014; Choat et al., 2008). The activation of more conduits under higher pressure gradients observed here substantiates the hypothesis that more conduits could be employed to overcome flow reductions due to damage, clogging, and/or gel release. Results from staining experiments further corroborate the redundancy of the xylem conductive system for normal or low flows (Korner, 2019), as supported by a recent study showing that a tree stem may be cut in half with minimal effect on the canopy water relations (Dietrich et al., 2018).

\subsection{How much hydraulic gradient is needed to induce flow?}

Systematic observations in our experiments and elsewhere (Dixon, 1914) suggest that very small gradients (e.g., $\Delta h / L \geq 1 \mathrm{~m} / \mathrm{m}$ ) were sufficient to sustain the flow through the branches. This is in line with theoretical predictions of transpiration fluxes computed from Eq. (1) for different sapwood areas and pressure gradients as a function of $K_{x}$ (Fig. 9). The comparison with published estimates of hourly transpiration per unit of leaf obtained from multi-year ecohydrological simulations supports that gradients of $4 \mathrm{~m} / \mathrm{m}$ are sufficient to sustain maximum transpiration fluxes and that hydraulic gradients substantially exceeding this value might be very rarely needed in plants and, if so, likely being only observed in the most distal parts (Hellkvist et al., 1974; Domec and Gartner, 2002). This also confirms the large redundancy of the xylem hydraulic conductivity in satisfying the transpiration fluxes under 
normal operating conditions (e.g., lower than 80 percentile - see Fig. S16). For these conditions half or a quarter of observed $K_{x}$ could sustain the transpiration demand at still relatively small gradients of 1 to $4 \mathrm{~m} / \mathrm{m}$. Finally, such low gradients support the notion that highest resistance with most of the head loss in the plant vasculature occurs in the leaves (Sack et al., 2003; Sack and Holbrook, 2006).

\subsection{Broader impacts}

The various methodological challenges in xylem conductivity measurements reinforce the longstanding recommendations for standardized protocol for xylem hydraulic measurements (Pratt et al., 2008; Espino and Schenk, 2010). These are important for systematic comparisons of measurements across species, locations, and conditions to advance understanding of plants' vascular system and hydraulic functioning. Specifically, measured $K_{x}$ values were shown to depend upon the different definitions of conductive area as well as re-saturation procedures, experiment duration, and pressure gradient applied. Current interpretation of xylem functioning and sapflow measurements needs to be revised in light of the observed dependence of xylem conductivity values on the applied pressure gradient and active tissue response to external forcings. This has several implications for xylem flow conceptualization as well as modeling applications, where the use of literature $K_{x}$ values might not be representative of real operating conditions.

New generation Earth System Models start considering explicitly plant hydraulics and consequently values of $K_{x}$ are needed to quantify plant water transport and transpiration (Bonan et al., 2014; Xu et al., 2016; Christoffersen et al., 2016, Kennedy et al., 2019). Concurrently, $K_{x}$ is often required in more specialized ecophysiological and ecohydrological models (e.g., Manzoni et al., 2013; Fatichi et al., 2016; Manoli et al., 2017). In all these modeling applications, special care should be taken in defining $K_{x}$, as assuming it a constant value could represent an oversimplification since $K_{x}$ might vary in response to biotic and abiotic stresses (see also Millar et al., 2017), as well as in response to 
pressure gradients and their history. The highlighted linkages between the macroscopic and microscopic behaviors point to the necessity to better relate the bulk hydraulic parameterization to the xylem network topology accounting explicitly for pressure-dependence flow paths and thus for a redundant network during normal operating conditions (Manzoni et al., 2013; Mrad et al., 2018; Bouda et al., 2019).

\section{Acknowledgements}

We acknowledge funding from ETH Zürich and inspiring discussions with Maciej Zwieniecki (UC Davis, USA) and Stan Schymanski (LIST Luxemburg) during the early phases of this study. We further thank Stefano Manzoni (Stockholm University) for sharing data. This work was also supported by the SEA EUROPE JFS020 program (project CWSSEA), an ANR project (PRIMA-SWATCH), and the NSF-IOS (\#1754893).

\section{Conflict of Interest}

The Authors declare that there is no conflict of interest.

\section{References:}

Bauerle, W.L., T.M. Hinckley, J. Èermák, J. Kuèera and K. Bible (1999). The canopy water relations of old-growth Douglas-fir trees. Trees, 13, 211-217.

Beikircher, B. and S. Mayr (2009), Intraspecific differences in drought tolerance and acclimation in hydraulics of Ligustrum vulgare and Viburnum lantana, Tree Physiology, 29(6), 765-775. 
Bonan, G. B., M. Williams, R. A. Fisher, and K. W. Oleson (2014), Modeling stomatal conductance in the Earth system: linking leaf water-use efficiency and water transport along the soil-plantatmosphere continuum, Geoscientific Model Development, 7,2193-2222.

Bouche, P. S., S. Jansen, H. Cochard, R. Burlett, G. Capdeville, and S. Delzon (2015). Embolism resistance of conifer roots can be accurately measured with the flow-centrifuge method, Journal of Plant Hydraulics, 2, e002, https://doi.org/10.20870/jph.2015.e002.

Bouda, M., C. W. Windt, A. J. McElrone, and C. R. Brodersen (2019), In vivo pressure gradient heterogeneity increases flow contribution of small diameter vessels in grapevine, Nature Communications, 10(1), 1-10.

Brodersen, C., S. Jansen, B. Choat, C. Rico, and J. Pittermann (2014), Cavitation resistance in seedless vascular plants: the structure and function of interconduit pit membranes, Plant Physiology, 165(2), 895-904.

Brown, H. R. (2013), The theory of the rise of sap in trees: some historical and conceptual remarks, Physics in Perspective, 15(3), 320-358.

Canny, M. J., J. P. Sparks, C. X. Huang, and M. L. Roderick (2007), Air embolisms exsolving in the transpiration water-the effect of constrictions in the xylem pipes, Functional Plant Biology, 34(2), 95-111.

Choat, B., A. R. Cobb, and S. Jansen (2008), Structure and function of bordered pits: new discoveries and impacts on whole-plant hydraulic function, New Phytologist, 177(3), 608-626.

Christoffersen, B. O., M. Gloor, S. Fauset, N. M. Fyllas, D. R. Galbraith, T. R. Baker, et al. (2016), Linking hydraulic traits to tropical forest function in a size-structured and trait-driven model (TFS v.1-Hydro), Geoscientific Model Development, 9(11), 4227-4255. 
Cochard, H., G. Damour, C. Bodet, I. Tharwat, M. Poirier, and T. Améglio (2005), Evaluation of a new centrifuge technique for rapid generation of xylem vulnerability curves, Physiologia Plantarum, 124(4), 410-418.

Cochard, H., Herbette, S., Hernández, E., Hölttä, T. and Mencuccini, M., (2009), The effects of sap ionic composition on xylem vulnerability to cavitation, Journal of Experimental Botany, 61(1), 275-285.

Crews, L.J., M. E. McCully, and M. J. Canny (2003), Mucilage production by wounded xylem tissue of maize roots—-time course and stimulus, Functional Plant Biology, 30(7), 755-766.

De Micco, V., A. Balzano, E. A. Wheeler, and P. Baas (2016), Tyloses and gums: a review of structure, function and occurrence of vessel occlusions, IAWA Journal, 37(2), 186-205.

Dietrich, L., G. Hoch, A. Kahmen, and C. Körner (2018), Losing half the conductive area hardly impacts the water status of mature trees, Scientific Reports, 8(1), 15,006.

Dixon, H. H. (1914), Transpiration and the ascent of sap in plants, Macmillan and Company, limited.

Dixon, H. H., and J. Joly (1895), Xii. On the ascent of sap, Philosophical Transactions of the Royal Society of London B , (186), 563-576.

Domec, J-C., and B. L. Gartner (2002), Age- and position-related changes in hydraulic vs. mechanical dysfunction of xylem: inferring the design criteria for Douglas-fir wood structure, Tree Physiology, 22, 91-104.

Domec, J-C., B.L. Lachenbruch, and F.C. Meinzer (2006), Bordered pit structure and function determine spatial patterns of air-seeding thresholds in xylem of Douglas-fir (Pseudostuga menziesii; Pinaceae) trees, American Journal of Botany, 93, 1588-1600.

Domec, J.-C., F. C. Meinzer, B. Lachenbruch, and J. Housset (2007), Dynamic variation in sapwood specific conductivity in six woody species, Tree physiology, 27(10), 1389-1400. 
Espino, S., and H. J. Schenk (2010), Mind the bubbles: achieving stable measurements of maximum hydraulic conductivity through woody plant samples, Journal of Experimental Botany, 62(3), $1119-1132$.

Fatichi, S., C. Pappas, and V. Y. Ivanov (2016), Modeling plant-water interactions: an ecohydrological overview from the cell to the global scale, Wiley Interdisciplinary Reviews: Water, 3(3), 327-368.

Fatichi S., and C. Pappas (2017), Constrained variability of modeled T:ET ratio across biomes, Geophysical Research Letters, 44(13), 6795-6803, doi:10.1002/2017GL074041.

Giordano, R., A. Salleo, S. Salleo, and F. Wanderlingh (1978), Flow in xylem vessels and Poiseuille’s law, Canadian Journal of Botany, 56(3), 333-338.

Glass, S. V., and S. L. Zelinka (2010), Moisture relations and physical properties of wood, in Wood Handbook, chapter 4. US Forest Service Forest Products Laboratory, Madison, Wisconsin.

Hacke, U.G., V. Stiller, J. S. Sperry, J. Pittermann, and K. A. McCulloh (2001), Cavitation fatigue. Embolism and refilling cycles can weaken the cavitation resistance of xylem, Plant Physiology, 125(2), 779-786.

Hellkvist, J., G.P. Richards, and P.G. Jarvis (1974), Vertical gradients of water potential and tissue water relations in Sitka Spruce trees measured with the pressure chamber, Journal of Applied Ecology, $11,637-667$.

Hillabrand, R.M., U. G. Hacke, and V. J. Lieffers (2016), Drought-induced xylem pit membrane damage in aspen and balsam poplar. Plant, Cell \& Environment, 39(10), 2210-2220.

Jacobsen, A.L., R. B. Pratt, M. F. Tobin, U. G. Hacke, and F. W. Ewers (2012), A global analysis of xylem vessel length in woody plants, American Journal of Botany, 99(10), 1583-1591. 
Jacobsen, A.L., and R. B. Pratt (2012), No evidence for an open vessel effect in centrifuge-based vulnerability curves of a long-vesselled liana (Vitis vinifera), New Phytologist, 194(4), 982-990.

Jacobsen, A. L., F. D. Rodriguez-Zaccaro, T. F. Lee, J. Valdovinos, H. S. Toschi, J. A. Martinez, and R. B. Pratt (2015), Grapevine xylem development, architecture, and function, in Functional and ecological xylem anatomy, pp. 133-162, Springer.

Jacobsen, A. L., J. Valdovinos-Ayala, and R. B. Pratt (2018), Functional lifespans of xylem vessels: Development, hydraulic function, and post-function of vessels in several species of woody plants, American Journal of Botany, 105(2), 142-150.

Jensen, K. H., K. Berg-Sørensen, H. Bruus, N. M. Holbrook, J. Liesche, A. Schulz, M. A. Zwieniecki, and T. Bohr (2016), Sap flow and sugar transport in plants, Reviews of Modern Physics, 88(3), 035,007.

Kattge, J., S. Diaz, S. Lavorel, I. C. Prentice, P. Leadley, G. B”onisch, E. Garnier, M. Westoby, P. B. Reich, I. J. Wright, et al. (2011), TRY - a global database of plant traits, Global Change Biology, 17(9), 2905-2935.

Kattge, J, G. Bönisch, S. Díaz, et al. (2020), TRY plant trait database - enhanced coverage and open access, Global Change Biology, 26: 119-188, https://doi.org/10.1111/gcb.14904.

Kelso, W. C., R. Gertjejansen, and R. L. Hossfeld (1963), The effect of air blockage upon the permeability of wood to liquids, Minnesota Agricultural Experiment Station.

Kennedy, D., S. Swenson, K. W. Oleson, D. M. Lawrence, R. Fisher, A. C. Lola da Costa, and P. Gentine (2019), Implementing plant hydraulics in the Community Land Model, version 5, Journal of Advances in Modeling Earth Systems, 11, 485-513, https://doi.org/10.1029/2018MS001500. 
Kitin, P., S. L. Voelker, F. C. Meinzer, H. Beeckman, S. H. Strauss, and B. Lachenbruch, (2010) Tyloses and phenolic deposits in xylem vessels impede water transport in low-lignin transgenic poplars: a study by cryo-fluorescence microscopy, Plant Physiology, 154(2), 887-898.

Korner, C. (2019), No need for pipes when the well is dry-a comment on hydraulic failure in trees, Tree Physiology, doi:10.1093/treephys/tpz030.

Larcher, W. (2003), Physiological plant ecology: ecophysiology and stress physiology of functional groups, Springer Science \& Business Media.

Lens, F., J. S. Sperry, M. A. Christman, B. Choat, D. Rabaey, and S. Jansen (2011), Testing hypotheses that link wood anatomy to cavitation resistance and hydraulic conductivity in the genus Acer, New Phytologist, 190(3), 709-723.

López-Portillo, J., F. W . Ewers, and G. Angeles (2005), Sap salinity effects on xylem conductivity in two mangrove species, Plant, Cell \& Environment, 28(10), 1285-1292.

Manoli, G., C.W. Huang, S. Bonetti, J.-C. Domec, M. Marani, and G. Katul (2017), Competition for light and water in a coupled soil-plant system, Advances in Water Resources, 108, 216-230.

Manzoni, S., G. Vico, A. Porporato, and G. Katul (2013), Biological constraints on water transport in the soil-plant-atmosphere system, Advances in Water Resources, 51, 292-304.

Martín, J.A., A. Solla, M. Ruiz-Villar, and L. Gil (2013), Vessel length and conductivity of Ulmus branches: ontogenetic changes and relation to resistance to Dutch elm disease, Trees, 27(5), 12391248.

Martin-StPaul, N., S. Delzon, H. Cochard (2017), Plant resistance to drought depends on timely stomatal closure, Ecology Letters, 20,1437-1447. 
Mayr, S., B. Beikircher, M. A. Obkircher, and P. Schmid (2010), Hydraulic plasticity and limitations of alpine Rhododendron species, Oecologia, 164(2), 321-330.

Melcher, P. J., N. M. Holbrook, M. J. Burns, M. A. Zwieniecki, A. R. Cobb, T. J. Brodribb, B. Choat, and L. Sack (2012), Measurements of stem xylem hydraulic conductivity in the laboratory and field, Methods in Ecology and Evolution, 3(4), 685-694.

Millar, D. J., B. E. Ewers, D. S. Mackay, S. Peckham, D. E. Reed, and A. Sekoni (2017), Improving ecosystem-scale modeling of evapotranspiration using ecological mechanisms that account for compensatory responses following disturbance, Water Resources Research, 53, doi:10.1002/2017WR020823.

Monteith, J. L. (1995), A reinterpretation of stomatal responses to humidity, Plant Cell Environ, 18,357364.Nardini, A., A. Gasco, P. Trifil`o, M. A. Lo Gullo, and S. Salleo (2007), Ion-mediated enhancement of xylem hydraulic conductivity is not always suppressed by the presence of ca2+ in the sap, Journal of Experimental Botany, 58(10), 2609-2615.

Morris, H., L. Plavcová, M. Gorai, M. M. Klepsch, M. Kotowska, H. J. Schenk, and S. Jansen (2018), Vessel-associated cells in angiosperm xylem: Highly specialized living cells at the symplastapoplast boundary, American Journal of Botany, 105(2), 151-160.

Mrad, A., J.-C. Domec, C. W. Huang, F. Lens, and G. G. Katul (2018), A network model links wood anatomy to xylem tissue hydraulic behaviour and vulnerability to cavitation, Plant, Cell \& Environment, 41(12), 2718-2730.

Nardini, A., S. Salleo, and S. Jansen (2011), More than just a vulnerable pipeline: xylem physiology in the light of ion-mediated regulation of plant water transport, Journal of Experimental Botany, 62(14), 4701-4718. 
Olson, M.E. and J. A. Rosell (2013), Vessel diameter-stem diameter scaling across woody angiosperms and the ecological causes of xylem vessel diameter variation, New Phytologist, 197(4), pp.12041213.

Peel, A. (1965), On the conductivity of the xylem in trees, Annals of Botany, 29(1), 119-130.

Peters, R.L., P. Fonti, D. C. Frank, R. Poyatos, C. Pappas, A. Kahmen, V. Carraro, A. L. Prendin, L. Schneider, J. L. Baltzer, G. A. Baron-Gafford, L. Dietrich, I. Heinrich, R. L. Minor, O. Sonnentag, A. M. Matheny, M. G. Wightman, and K. Steppe (2018), Quantification of uncertainties in conifer sap flow measured with the thermal dissipation method, New Phytologyst, 219: 1283-1299. doi:10.1111/nph.15241

Petty, J.A. (1972), The aspiration of bordered pits in conifer wood. Proceedings of the Royal Society of London. Series B. Biological Sciences, 181(1065), 395-406.

Petty, J.A. and G. S. Puritch (1970), The effects of drying on the structure and permeability of the wood of Abies grandis, Wood Science and Technology, 4(2), 140-154.

Pickard, W. F. (1981), The ascent of sap in plants, Progress in Biophysics and Molecular Biology, 37, $181-229$.

Plavcová, L., S. Jansen, M. Klepsch, and U. G. Hacke (2013), Nobody’s perfect: can irregularities in pit structure influence vulnerability to cavitation?, Frontiers in Plant Science, 4, 453.

Pratt, R. B., A. L. Jacobsen, G. B. North, L. Sack, and H. J. Schenk (2008), Plant hydraulics: new discoveries in the pipeline, New Phytologist, 179(3), 590-593.

Rioux, D., M. Nicole, M. Simard, and G. B. Ouellette (1998), Immunocytochemical evidence that secretion of pectin occurs during gel (gum) and tylosis formation in trees, Phytopathology, 88(6), 494-505. 
Sack, L., P.D. Cowan, N. Jaikumar, and N. M. Holbrook (2003), The 'hydrology' of leaves: coordination of structure and function in temperate woody species, Plant, Cell \& Environment, 26(8), 1343-1356.

Sack, L. and N. M. Holbrook (2006), Leaf hydraulics, Annual Review of Plant Biology, 57, 361-381.

Schenk, H. J. (2018), Wood: Biology of a living tissue, American Journal of Botany, 105(2), 139-141.

Schenk, H.J., S. Espino, S. M. Rich-Cavazos, and S. Jansen (2018), From the sap's perspective: The nature of vessel surfaces in angiosperm xylem. American Journal of Botany, 105(2), 172-185.

Sperry, J., J. Donnelly, and M. Tyree (1988), A method for measuring hydraulic conductivity and embolism in xylem, Plant, Cell \& Environment, 11(1), 35-40.

Sperry, J.S. (2011), Hydraulics of vascular water transport, in Mechanical integration of plant cells and plants (pp. 303-327), Springer, Berlin, Heidelberg.

Stroock, A. D., V. V. Pagay, M. A. Zwieniecki, and N. Michele Holbrook (2014), The physicochemical hydrodynamics of vascular plants, Annual Review of Fluid Mechanics, 46, 615-642.

Sun, Q., Rost, T.L. and Matthews, M.A. (2008), Wound-induced vascular occlusions in Vitis vinifera (Vitaceae): Tyloses in summer and gels in winter, American Journal of Botany, 95(12), 1498-1505.

Tobin, M.F., R. B. Pratt, A. L. Jacobsen, and M. E. De Guzman (2013), Xylem vulnerability to cavitation can be accurately characterised in species with long vessels using a centrifuge method, Plant Biology, 15(3), 496-504.

Trifilò, P., M. A. Lo Gullo, S. Salleo, K. Callea, and A. Nardini (2008), Xylem embolism alleviated by ion-mediated increase in hydraulic conductivity of functional xylem: insights from field measurements, Tree Physiology, 28(10), 1505-1512. 
Tyree, M. T. (1997), The cohesion-tension theory of sap ascent: current controversies, Journal of Experimental Botany, 48(10), 1753-1765.

Tyree, M. T., and F.W. Ewers (1991), The hydraulic architecture of trees and other woody plants, New Phytologist, 119(3), 345-360.

Tyree, M. T., and M. Zimmermann (2002), Xylem structure and the ascent of sap, Springer-Verlag Berlin.

Tyree, M. T., S. Yang, P. Cruiziat, and B. Sinclair (1994), Novel methods of measuring hydraulic conductivity of tree root systems and interpretation using amaized (a maize-root dynamic model for water and solute transport), Plant Physiology, 104(1), 189-199.

Umebayashi, T., J. S. Sperry, D. D. Smith, and D. M. Love (2019), 'Pressure fatigue’: the influence of sap pressure cycles on cavitation vulnerability in Acer negundo, Tree Physiology, 39(5), 740-746.

Van den Honert, T. (1948), Water transport in plants as a catenary process, Discussions of the Faraday Society, 3, 146-153.

Van Ieperen, W., U. Van Meeteren, and H. Van Gelder (2000), Fluid ionic composition influences hydraulic conductance of xylem conduits, Journal of Experimental Botany, 51(345), 769-776.

Xu, X., D. Medvigy, J. S. Powers, J. M. Becknell, and K. Guan (2016), Diversity in plant hydraulic traits explains seasonal and inter-annual variations of vegetation dynamics in seasonally dry tropical forests, New Phytologist, 212, 80-95.

Zimmermann, M. H. (1978), Hydraulic architecture of some diffuse-porous trees, Canadian Journal of Botany, 56(18), 2286-2295.

Zwieniecki, M. A., P. J. Melcher, and N. M. Holbrook (2001), Hydrogel control of xylem hydraulic resistance in plants, Science, 291(5506), 1059-1062. 
Zwieniecki, M. A., P. J. Melcher, T. S. Feild, and N. M. Holbrook (2004), A potential role for xylemphloem interactions in the hydraulic architecture of trees: effects of phloem girdling on xylem hydraulic conductance, Tree Physiology, 24(8), 911-917.

a.
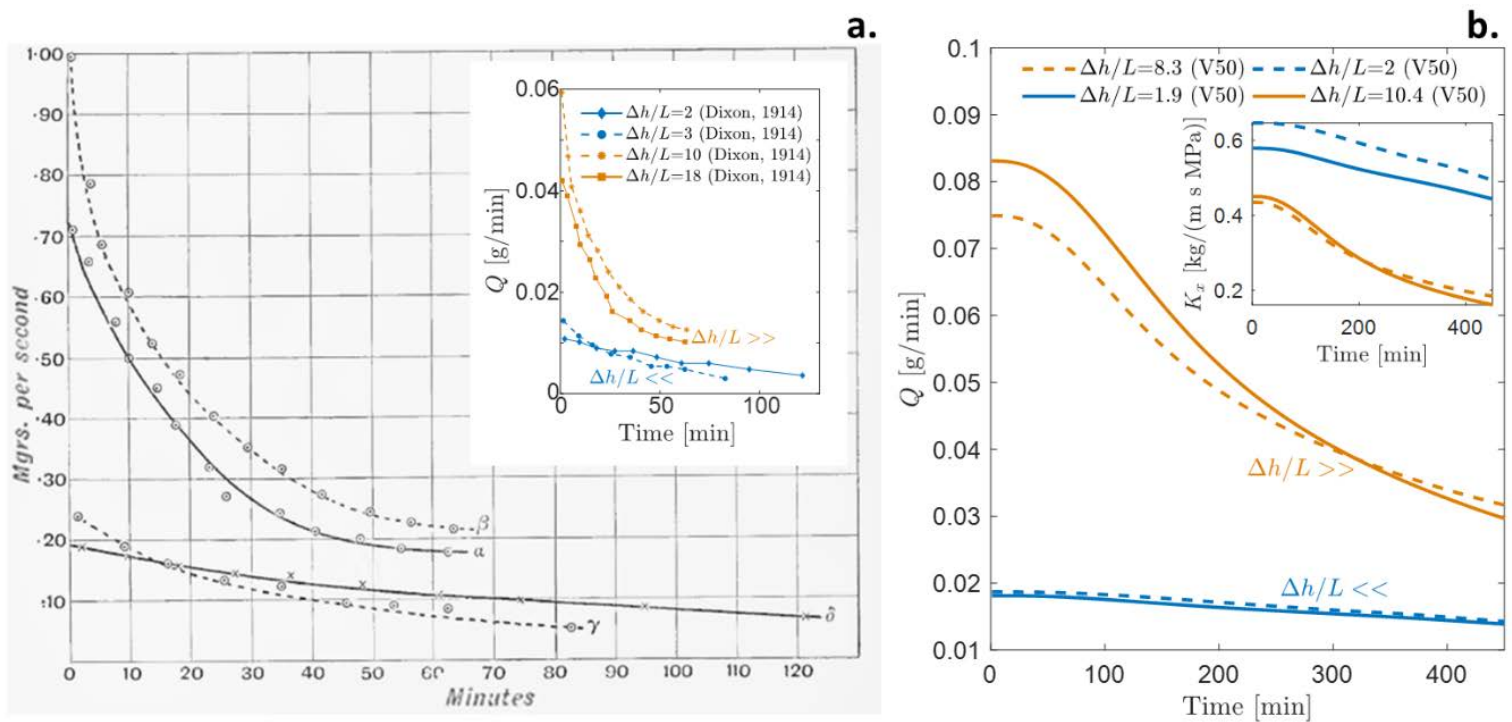

Fig. 1. Flow rate $Q$ as a function of time: (a) data from Dixon (1914) showing the measured flow rate in $\mathrm{mg} / \mathrm{s}$ for four branches of Abies pectinate (to allow comparison with panel $\mathrm{b}$, the inset shows the same digitized data in $\mathrm{g} / \mathrm{min}, \alpha, \beta, \gamma$, and $\delta$ in the original figure correspond to $\Delta h / L=18,10,2$, and $3 \mathrm{~m} / \mathrm{m}$ in the inset), (b) results obtained for four Lawson cypress (Chamaecyparis lawsoniana) branches from experiment V50. Results are shown for high (orange) and low (blue) values of $\Delta h / L$ $[\mathrm{m} / \mathrm{m}]$, defined as the ratio of hydrostatic pressure applied $(\Delta h)$ to branch length $(L)$. The inset in panel b shows the hydraulic conductivity $K_{x}$ computed according to Eq. (1) for experiment V50. 

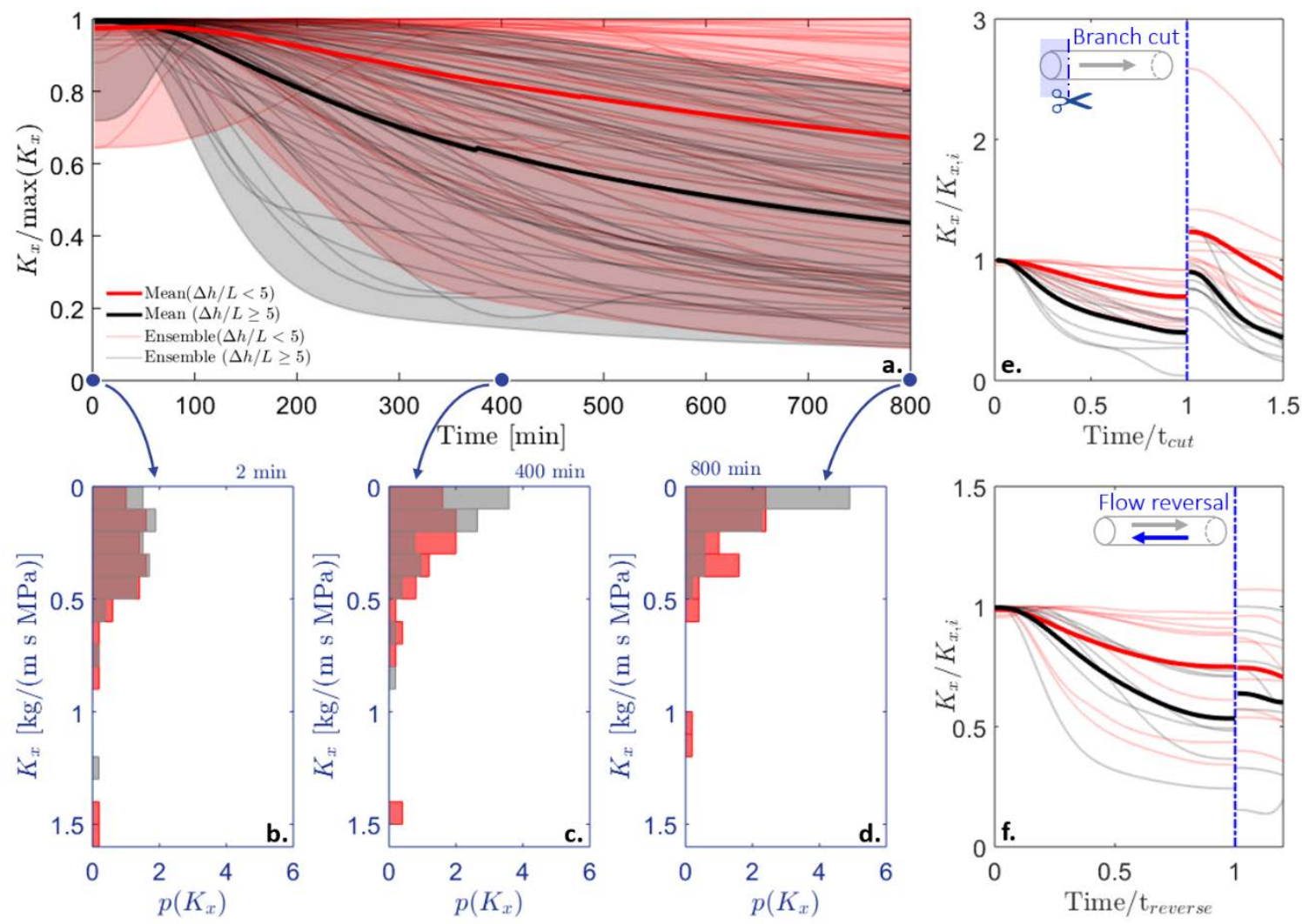

Fig. 2. (a) Results from constant (steady-state) pressure experiments: hydraulic conductivity $\left(K_{x}\right)$, normalized here by its maximum value for each experiment) obtained from experiments over branches of approximately $5 \mathrm{~cm}$ length. Probability density functions of $K_{x}$ values at (b) 2, (c) 400 , (d) 800 minutes from the beginning of the experiments. Results from (e) branch cutting and (f) flow reversal experiments: hydraulic conductivity $K_{x}$ (normalized by its initial value) as a function of time normalized by the time of branch cutting $\left(\mathrm{t}_{\text {cut }}\right)$ and time of flow reversal $\left(\mathrm{t}_{\text {reverse }}\right)$ - shown by the blue dash-dotted line. Red and gray/black refer to low $(\Delta h / L<5 \mathrm{~m} / \mathrm{m})$ and high $(\Delta h / L \geq 5 \mathrm{~m} / \mathrm{m})$ pressure gradients applied (thick lines show mean values over all the experiments). 

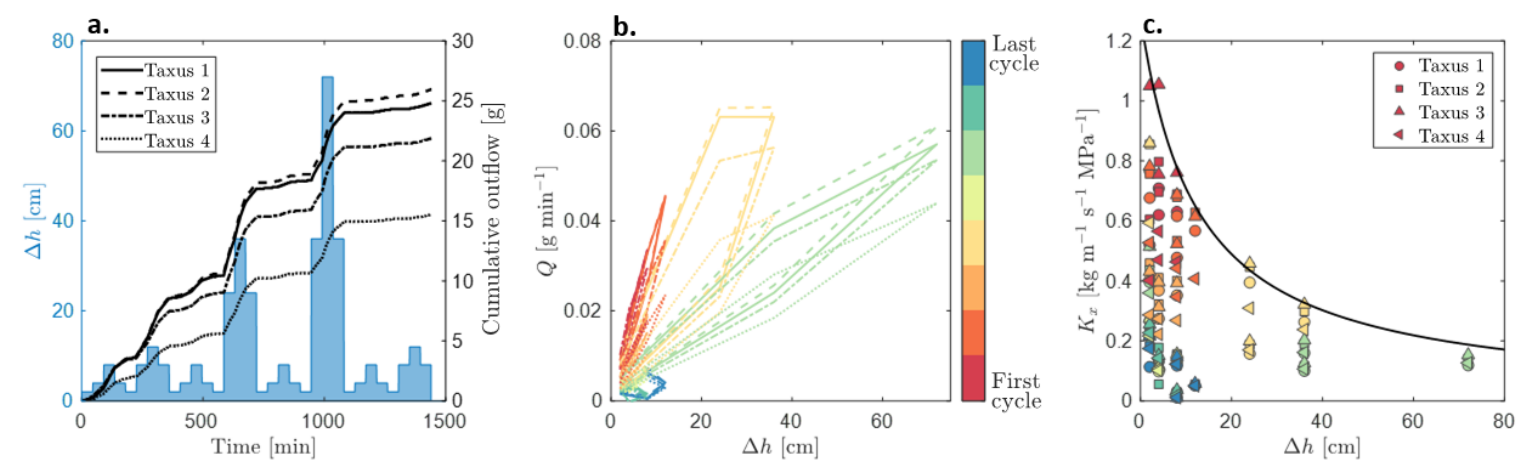

Fig. 3. Results from pressure cycles experiments for four European yew (Taxus baccata) branches (V34): (a) cumulative outflow (black) and pressure head cycles (blue), (b) flow rate $Q$, and (c) hydraulic conductivity $K_{x}$ as a function of the applied hydrostatic pressure heads $\Delta h$ (the black line marks highest conductivity envelope). 


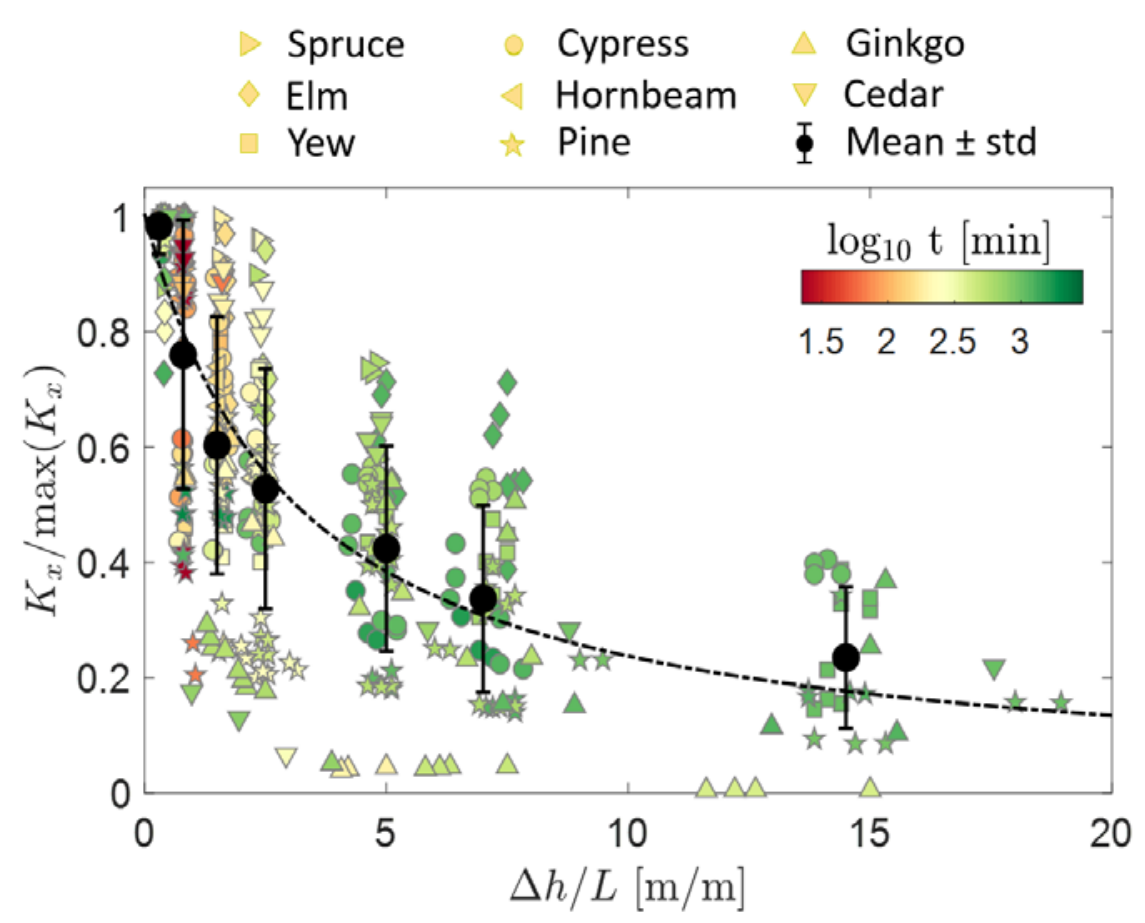

Fig. 4. Results from pressure cycles experiments across eight tree species: highest conductivity $\left(K_{x}\right)$ values (normalized by its maximum value for each experiment) obtained for each pressure gradient applied $(\Delta h / L)$. Different symbols refer to different species, black dots with error bars are mean values ( \pm one standard deviation) for each pressure gradient. The color bar indicates the time (from the beginning of each experiment) at which the maximum $K_{x}$ was observed for each pressure gradient. Species used for these experiments include Norway spruce (Picea abies), field elm (Ulmus minor), European yew (Taxus baccata), Lawson cypress (Chamaecyparis lawsoniana), European hornbeam (Carpinus betulus), Austrian pine (Pinus nigra), ginkgo (Ginkgo biloba), and Atlas cedar (Cedrus atlantica). 

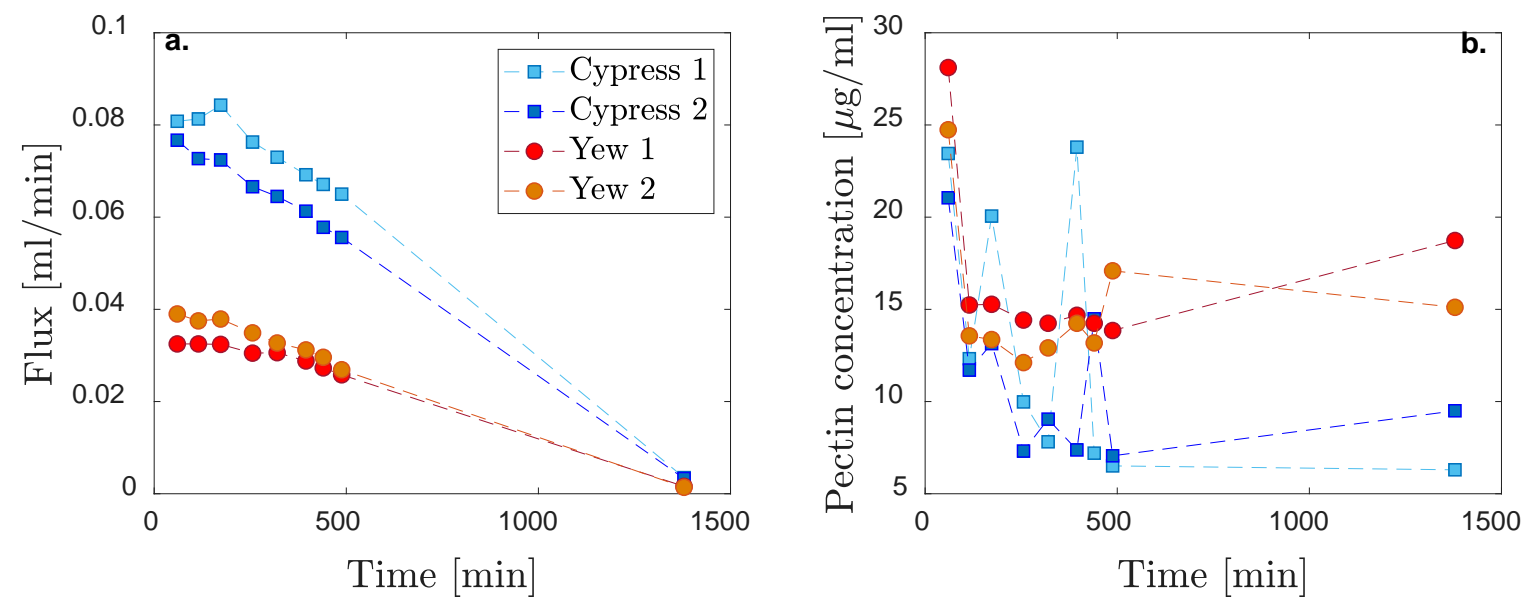

Fig. 5. (a) Measured flux and (b) pectin concentration for two Lawson cypress (Chamaecyparis lawsoniana, squares) and two European yew (Taxus baccata, circles) branches subjected to a pressure head $\Delta h$ of $60 \mathrm{~cm}$. Branches were approximately $6.5 \mathrm{~cm}$ long and had an average diameter of $6.7 \mathrm{~mm}$. 


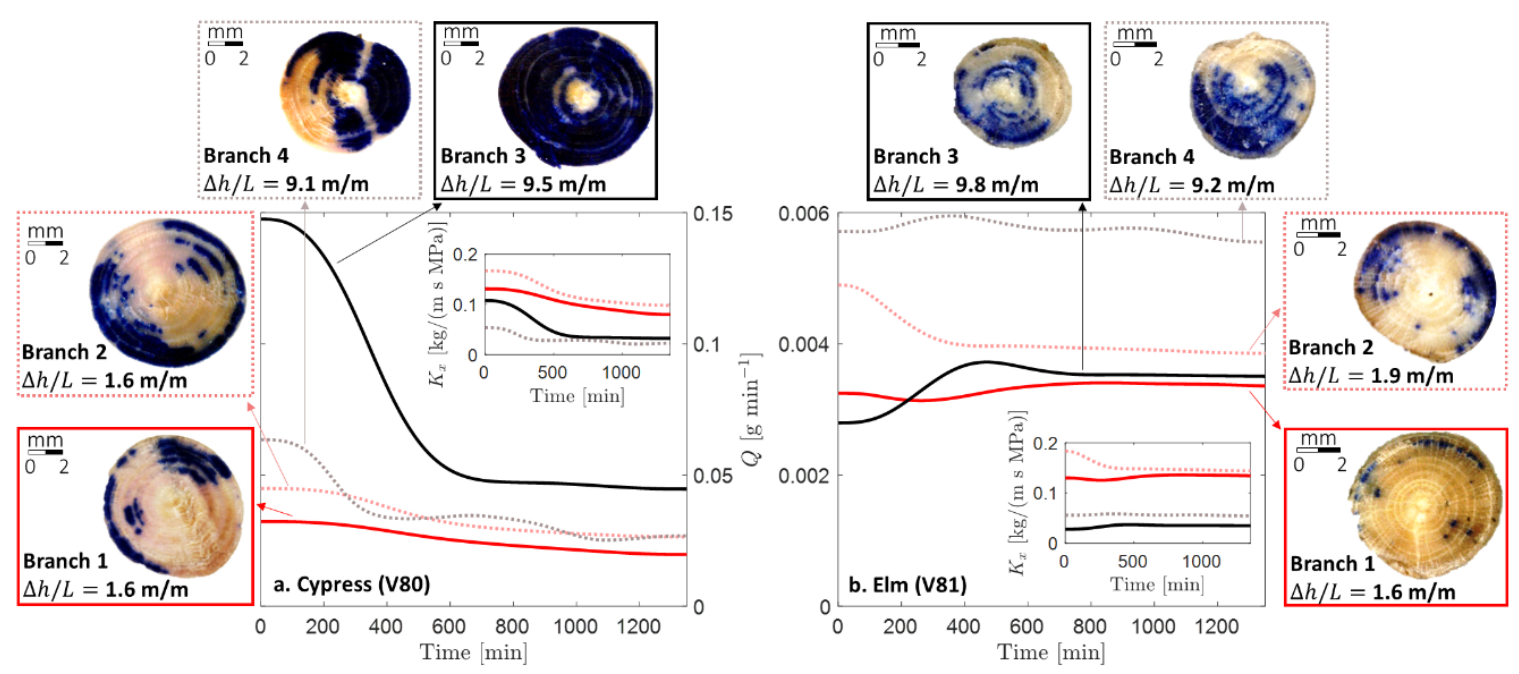

Fig. 6. Flow rate $Q$ as a function of time and pressure gradient $(\Delta h / \mathrm{L})$ for (a) four cypress (Chamaecyparis lawsoniana) branches (measurement V80) and (b) four elm (Ulmus minor) branches (measurement V81). Cross sections of the branches at $1 \mathrm{~cm}$ from the inlet are shown for each branch after staining using crystal violet (purple) to identify the active xylem vessels. Insets show the specific hydraulic conductivity $\left(K_{x}\right)$ computed assuming that the active xylem cross section $\left(A_{x}\right)$ was equal to the total branch cross section. 

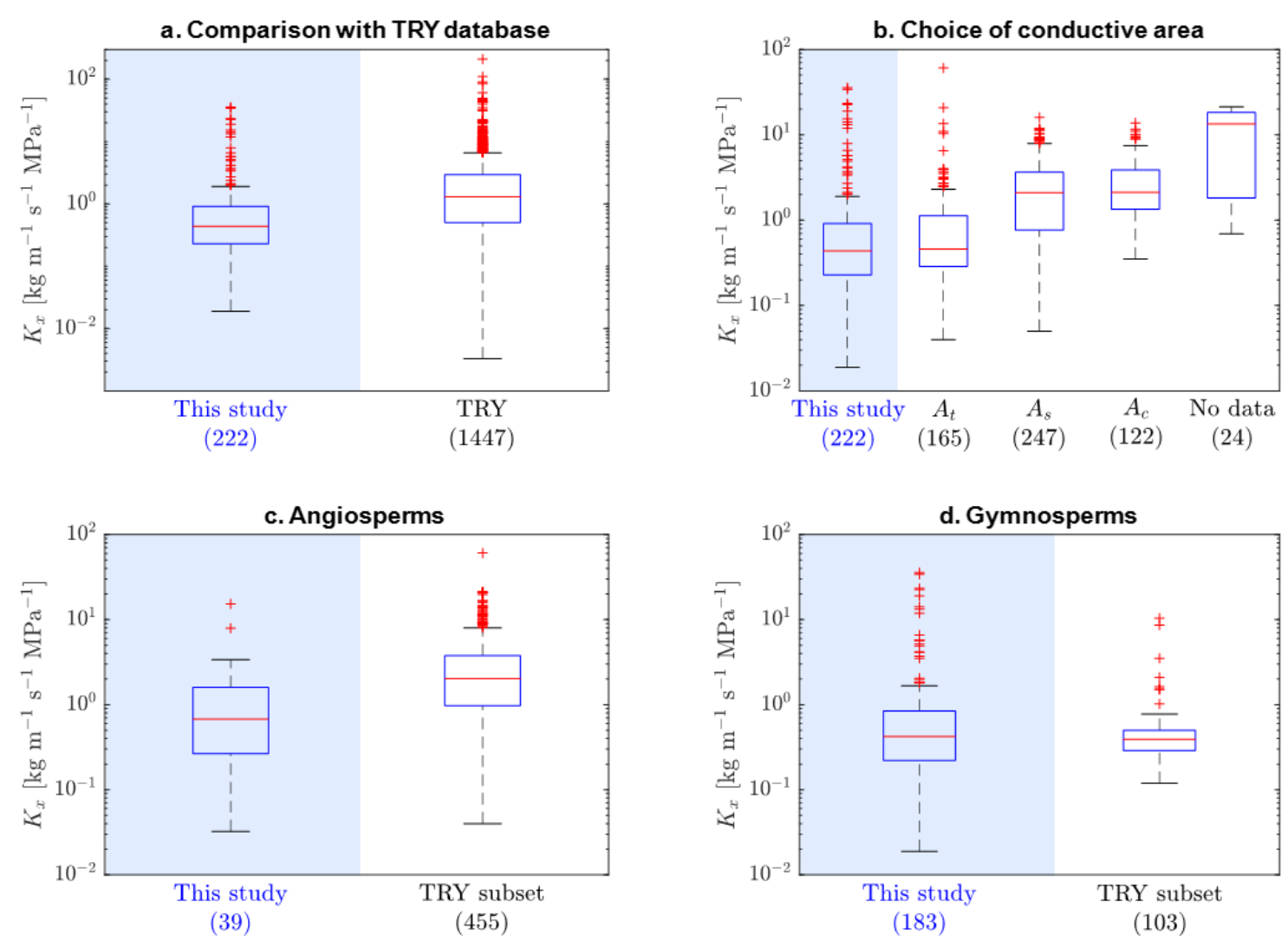

Fig. 7. Comparison with literature data. Results from this study (222 values comprising maximum conductivity $\left(K_{x}\right)$ from pressure cycles, constant pressure, and high pressure experiments) are contrasted with (a) 1447 measurements from the TRY dataset and (b,c,d) a subset of 558 measurements from Manzoni et al. (2013) (also included in the TRY database). Panels c and d compare $K_{x}$ values obtained from angiosperms and gymnosperms, respectively. In panel b the $K_{x}$ values from Manzoni et al. (2013) are subdivided according to definition of $A_{x}$ used in the computation of $K_{x}\left(A_{t}=\right.$ branch cross section excluding the bark, $A_{s}=$ branch cross section excluding pith, $A_{c}=$ conductive area obtained from staining, No data $=$ no clear information was provided on definition of $A_{x}$ ). The central red line indicates the median, and the bottom and top edges of the box indicate the $25^{\text {th }}$ and $75^{\text {th }}$ percentiles, respectively. The whiskers extend to the most extreme data 
points not considered outliers (i.e., 1.5 times the interquartile range from the ends of the box), and the outliers are plotted individually (+ symbol). Number of observations in each class are given in parenthesis. 
a. Resaturation experiments (V85, V86, V87)

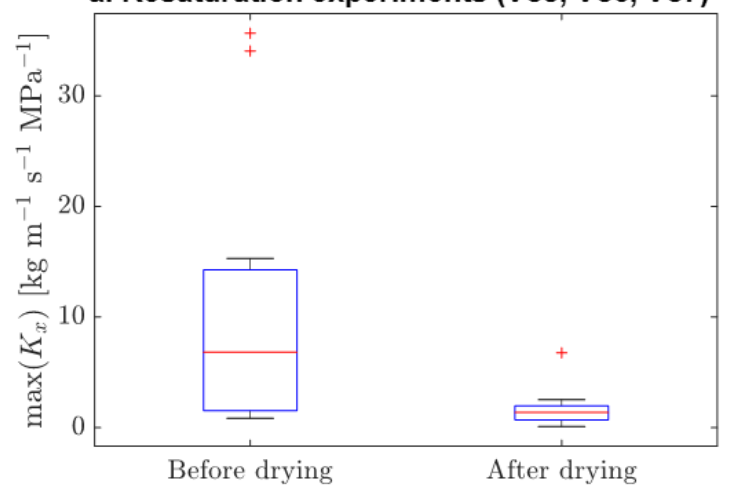

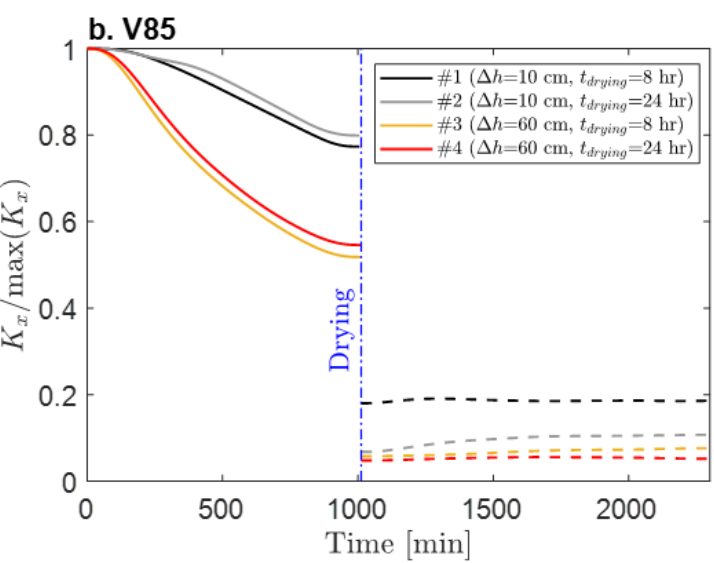

Fig. 8. Re-saturation experiments. (a) Boxplots of maximum hydraulic conductivity $\left(K_{x}\right)$ values obtained from experiments V85, V86, and V87 before and after drying with a fan for 8 to 24 hours (see Tab. S10 for experimental details). The central red line indicates the median, and the bottom and top edges of the box indicate the $25^{\text {th }}$ and $75^{\text {th }}$ percentiles, respectively. The whiskers extend to the most extreme data points not considered outliers (i.e., 1.5 times the interquartile range from the ends of the box), and the outliers are plotted individually (+ symbol). (b) Hydraulic conductivity $K_{x}$ (normalized by its initial value) as a function of time for experiment V85 (branches were dried with a fan for 8 or 24 hours). The blue dash-dotted line marks the time of drying, while solid and dashed lines are used for measurements before and after drying and re-saturation, respectively. 


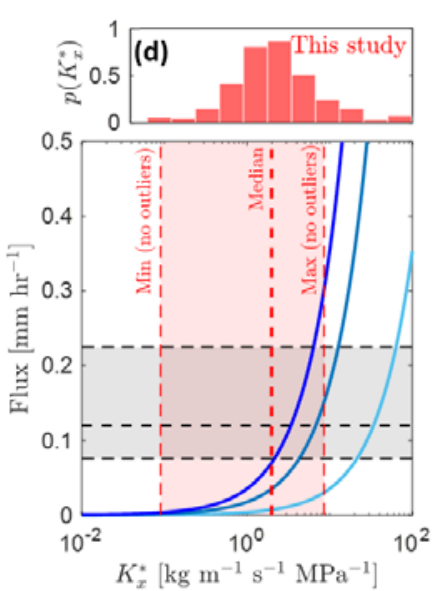

(a) $\Delta h / L=1 \mathrm{~m} / \mathrm{m}$

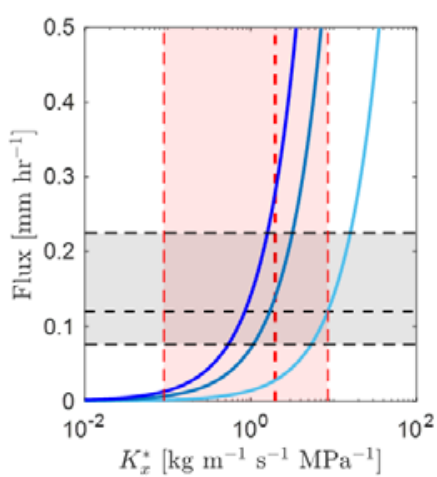

(b) $\Delta h / L=4 \mathrm{~m} / \mathrm{m}$

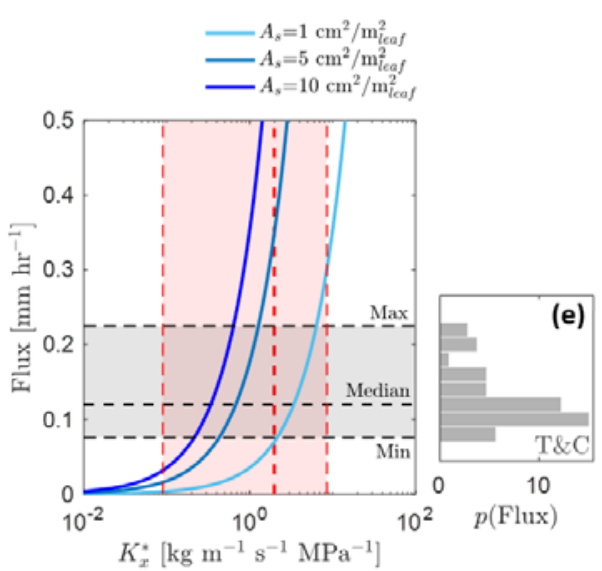

(c) $\Delta h / L=10 \mathrm{~m} / \mathrm{m}$

Fig. 9. (a,b,c) Transpiration flux (per unit leaf area) as a function of xylem specific hydraulic conductivity $\left(K_{x}\right)$ computed according to Eq. (1) for different values of sapwood area $A_{s}$ and pressure gradient $\Delta h / L$. The red dashed region shows the range of xylem hydraulic conductivities (excluding outliers) from this study (see probability distribution in panel d). The measured $K_{x}$ is here rescaled by a factor of $4.5\left(K_{x}^{*}=4.5 \cdot K_{x}\right)$ to account for the sapwood to cross sectional area difference (as obtained from the TRY database) in the definition of conductive area (see text for details). The gray dashed region shows the range of the 99 percentile of transpiration fluxes computed with the ecohydrological model T\&C for 53 woody ecosystems (see SI for details, the probability distribution of the transpiration values is given in panel e). 
Tab. 1. Constant pressure, branch cutting, and flow reversal experiments: number of branch samples ( $\mathrm{N}_{\text {samples}}$ ), mean diameter $(\bar{d}$, excluding bark), mean branch length $(\bar{L})$, minimum and maximum pressure heads applied $(\Delta h)$, and mean value of the maximum hydraulic conductivity $\overline{K_{x}}$ for each species analyzed. Note that, given the small number of samples for certain species, only mean values are reported. Detailed information for each branch is provided in Tables S3, S5, and S6.

\begin{tabular}{|c|c|c|c|c|c|}
\hline Species & $\mathbf{N}_{\text {samples }}$ & $\begin{array}{c}\bar{d} \\
{[\mathrm{~mm}]}\end{array}$ & $\begin{array}{c}\bar{L} \\
{[\mathrm{~mm}]}\end{array}$ & $\begin{array}{c}\Delta h(\min , \max ) \\
{[\mathrm{cm}]}\end{array}$ & $\begin{array}{c}\overline{K_{x}} \\
{[\mathrm{~kg} /(\mathrm{m} \mathrm{s} \mathrm{MPa})]}\end{array}$ \\
\hline \multicolumn{6}{|c|}{ Constant pressure experiments } \\
\hline $\begin{array}{l}\text { Lawson cypress } \\
\text { (Chamaecyparis } \\
\text { lawsoniana) }\end{array}$ & 18 & 6.7 & 50.6 & 10,90 & 0.30 \\
\hline $\begin{array}{l}\text { Austrian pine } \\
\text { (Pinus nigra) }\end{array}$ & 12 & 5.4 & 51.8 & 10,90 & 0.35 \\
\hline $\begin{array}{l}\text { Atlas cedar } \\
\text { (Cedrus atlantica) } \\
\text { Giant sequoia }\end{array}$ & 8 & 5.2 & 52.6 & 10,60 & 0.29 \\
\hline $\begin{array}{l}\text { (Sequoiadendron } \\
\text { giganteum) }\end{array}$ & 6 & 6.2 & 51.8 & 10,90 & 0.48 \\
\hline $\begin{array}{l}\text { European yew } \\
\text { (Taxus baccata) }\end{array}$ & 4 & 5.6 & 51.3 & 10,50 & 0.31 \\
\hline $\begin{array}{l}\text { Field elm } \\
\text { (Ulmus minor) }\end{array}$ & 4 & 5.7 & 50.3 & 10,50 & 0.16 \\
\hline $\begin{array}{l}\text { Norway spruce } \\
\text { (Picea abies) }\end{array}$ & 2 & 6.4 & 51.5 & 10,50 & 0.11 \\
\hline $\begin{array}{l}\text { Ginkgo } \\
\text { (Ginkgo biloba) }\end{array}$ & 2 & 5.7 & 50.0 & 10,50 & 0.70 \\
\hline $\begin{array}{l}\text { European hornbeam } \\
\text { (Carpinus betulus) }\end{array}$ & 2 & 6.7 & 51.0 & 10,50 & 0.66 \\
\hline
\end{tabular}

\section{Branch cutting experiments}

\begin{tabular}{|c|c|c|c|c|c|}
\hline $\begin{array}{l}\text { Lawson cypress } \\
\text { (Chamaecyparis } \\
\text { wsoniana) }\end{array}$ & 9 & 5.5 & $\begin{array}{c}75.2 \text { (before cut) } \\
44.9 \text { (after cut) }\end{array}$ & 10,60 & $\begin{array}{c}0.42 \text { (before cut) } \\
0.39 \text { (after cut) }\end{array}$ \\
\hline $\begin{array}{l}\text { Atlas cedar } \\
\text { (Cedrus atlantica) }\end{array}$ & 4 & 6.8 & $\begin{array}{c}86.3 \text { (before cut) } \\
71.0 \text { (after cut) }\end{array}$ & 10,60 & $\begin{array}{c}0.24 \text { (before cut) } \\
0.25 \text { (after cut) }\end{array}$ \\
\hline $\begin{array}{l}\text { Turkish hazel } \\
\text { (Corylus colurna) }\end{array}$ & 3 & 6.4 & $\begin{array}{l}75.7 \text { (before cut) } \\
61.0 \text { (after cut) }\end{array}$ & 10,60 & $\begin{array}{l}1.51 \text { (before cut) } \\
1.37 \text { (after cut) }\end{array}$ \\
\hline $\begin{array}{l}\text { Field elm } \\
\text { (Ulmus minor) }\end{array}$ & 2 & 5.8 & $\begin{array}{l}47.5 \text { (before cut) } \\
32 \text { (after cut) }\end{array}$ & 10,60 & $\begin{array}{c}0.09 \text { (before cut) } \\
0.19 \text { (after cut) }\end{array}$ \\
\hline \multicolumn{6}{|c|}{ Flow reversal experiments } \\
\hline $\begin{array}{l}\text { Lawson cypress } \\
\text { (Chamaecyparis } \\
\text { lawsoniana) }\end{array}$ & 6 & 5.8 & 55.3 & 10,60 & $\begin{array}{c}0.19 \text { (before reversal) } \\
0.15 \text { (after reversal) }\end{array}$ \\
\hline $\begin{array}{l}\text { European yew } \\
\text { (Taxus baccata) }\end{array}$ & 4 & 4.1 & 57.3 & 10,60 & $\begin{array}{c}0.13 \text { (before reversal) } \\
0.08 \text { (after reversal) }\end{array}$ \\
\hline Atlas cedar & 3 & 8.1 & 88.0 & 10,60 & 0.13 (before reversal) \\
\hline
\end{tabular}


(Cedrus atlantica)

European hornbeam

(Carpinus betulus)

2

6.9

50.5

10,60

0.07 (after reversal)

1.3 (before reversal)

0.72 (after reversal)

This article is protected by copyright. All rights reserved. 
Tab. 2. Pressure cycles, re-saturation, pressure tank, and staining experiments: number of branch samples ( $\mathrm{N}_{\text {samples }}$ ), mean diameter $(\bar{d}$, excluding bark), mean branch length $(\bar{L})$, minimum and maximum pressure heads applied $(\Delta h)$, and mean value of the maximum hydraulic conductivity $\overline{K_{x}}$ for each species analyzed. Note that, given the small number of samples for certain species, only mean values are reported. Detailed information for each branch are provided in Tables. S7-S11.

\begin{tabular}{|c|c|c|c|c|c|}
\hline Species & $\mathbf{N}_{\text {samples }}$ & $\begin{array}{c}\bar{d} \\
{[\mathrm{~mm}]}\end{array}$ & $\begin{array}{c}\bar{L} \\
{[\mathrm{~mm}]}\end{array}$ & $\begin{array}{c}\Delta h(\min , \max ) \\
{[\mathrm{cm}]}\end{array}$ & $\begin{array}{c}\overline{K_{x}} \\
{[\mathrm{~kg} /(\mathbf{m ~ s ~ M P a})]}\end{array}$ \\
\hline \multicolumn{6}{|l|}{ Pressure cycles experiments } \\
\hline $\begin{array}{l}\text { Austrian pine } \\
\text { (Pinus nigra) }\end{array}$ & 18 & 6.1 & 48.1 & 2,72 & 0.93 \\
\hline $\begin{array}{l}\text { Lawson cypress } \\
\text { (Chamaecyparis lawsoniana) }\end{array}$ & 15 & 6.3 & 51.4 & 2,72 & 0.42 \\
\hline $\begin{array}{l}\text { Ginkgo } \\
\text { (Ginkgo biloba) }\end{array}$ & 8 & 6.6 & 52.5 & 2,72 & 2.67 \\
\hline $\begin{array}{l}\text { European yew } \\
\text { (Taxus baccata) }\end{array}$ & 8 & 6.1 & 50.0 & 2,72 & 0.90 \\
\hline $\begin{array}{l}\text { Field elm } \\
\text { (Ulmus minor) }\end{array}$ & 7 & 5.6 & 48.0 & 2, 36 & 0.43 \\
\hline $\begin{array}{l}\text { Atlas cedar } \\
\text { (Cedrus atlantica) }\end{array}$ & 5 & 6.5 & 48.2 & 2,72 & 0.70 \\
\hline $\begin{array}{l}\text { Norway spruce } \\
\text { (Picea abies) }\end{array}$ & 4 & 6.0 & 50.8 & 2,24 & 0.49 \\
\hline $\begin{array}{l}\text { European hornbeam } \\
\text { (Carpinus betulus) }\end{array}$ & 3 & 4.5 & 52.3 & 2,12 & 2.00 \\
\hline
\end{tabular}

\section{Re-saturation experiments}

\begin{tabular}{|c|c|c|c|c|c|}
\hline $\begin{array}{l}\text { Lawson cypress } \\
\text { (Chamaecyparis lawsoniana) }\end{array}$ & 12 & 7.3 & $\begin{array}{l}70.2 \text { (before res.) } \\
56.8 \text { (after res.) }\end{array}$ & 10,60 & $\begin{array}{c}13.15 \text { (before res.) } \\
3.40 \text { (after res.) }\end{array}$ \\
\hline $\begin{array}{l}\text { Field elm } \\
\text { (Ulmus minor) }\end{array}$ & 4 & 5.6 & $\begin{array}{l}76.8 \text { (before res.) } \\
61.3 \text { (after res.) }\end{array}$ & 10,60 & $\begin{array}{l}6.36 \text { (before cut) } \\
3.03 \text { (after cut) }\end{array}$ \\
\hline
\end{tabular}

\section{Pressure tank experiments}

T awson cypress

(Chamaecyparis lawsoniana)

Silver birch

(Betula pendula)

Giant sequoia

(Sequoiadendron giganteum)

Norway maple

(Acer platanoides)

Austrian pine

(Pinus nigra)

Atlas cedar

(Cedrus atlantica)

Turkish hazel

(Corylus colurna)

European yew

$\begin{array}{lllll}8 & 4.5 & 40 & 5.1,407.6 & 1.10 \\ 5 & 4.0 & 40 & 5.1,407.6 & 1.93 \\ 3 & 4.6 & 40 & 10.2,356.6 & 0.70 \\ 3 & 3.2 & 40 & 5.1,203.8 & 0.74 \\ 1 & 4.2 & 40 & 30.57,305.7 & 0.02 \\ 1 & 4.0 & 40 & 30.57,305.7 & 0.02 \\ 1 & 4.8 & 40 & 22.4,152.8 & 0.46 \\ 1 & 4.4 & 40 & 30.57,305.7 & 0.02\end{array}$


(Taxus baccata)

European hornbeam

1

$6.4 \quad 40$

$22.4,152.8$

0.22

\section{Staining experiments}

Lawson cypress

(Chamaecyparis lawsoniana)

4

Field elm

(Ulmus minor)

8.0

63.5

10,60

1.27

4

5.3

60.5

10,60

0.97

This article is protected by copyright. All rights reserved. 
Summary statement for "Persistent decay of fresh xylem hydraulic conductivity varies with pressure gradient and marks plant responses to injury” by Bonetti et al.

Xylem flow measurements using freshly cut branches show temporal and pressure-dependent decrease in xylem hydraulic conductivity with active wound response of living xylem tissue. Results have notable implications for plant water relations and xylem conceptualization as a complex living system. 